\title{
Technological and Societal Changes in School Management
}

\author{
Maria Cristina Serb (Tanislav) \\ crisstinaro@yahoo.com \\ Valahia University of Targoviste, Romania
}

\begin{abstract}
Globalization and technological change processes have created a new global "technologydriven, knowledge-driven, information-driven economy". This study tried to analyse the strategies that educational system managers apply to improve management through the impact of technology in high school of Dambovita County, Romania. The study is based on a survey based on a questionnaire on a sample of 30 high schools and 309 subjects. The results allow us to get an overview of the implementation and integration of digitization innovation in the secondary schools in Dambovita County, thus having the opportunity to observe the main advances in the evolution of the educational management.
\end{abstract}

Keywords: globalization, digital society, education, changes, school

JEL code: $\mathrm{O} 33$

\section{Introduction}

In the last decades, it is increasingly focusing on a new managerial optics, with a holistic vision, characterized by autonomy and complementarity, giving up the pyramid vision. The development of the school organization is the product of a multitude of factors, but the management factor has a visible influence, representing an integrative dimension that unites in a structured all the other characteristics of the organization (Păun, 1999).

There are four key components that help public schoolmasters lead without having to control (Senge, 2016): involvement, systematic thinking, learning leadership, self-awareness. The main reason for the outstanding performance of teachers in a school is the support they receive from the school headmaster. The factor influencing is given by the nature of the leadership by (Boyd et al., 2011):

- motivating teachers and performing students;

- consulting the teaching staff with regard to the decisions affecting them;

- encouraging communication;

- allocation of resources;

- the development of the organizational structures with a role in supporting training and learning, as well as in the constant assessment of students' level of learning.

In the current context, it is necessary to cooperate at the level of an educational system to valorise creativity and innovation at the class level. Improving the institutional capacity of educational establishments is an important point in adapting teaching methods to the learning style of current and future generations. The system must be accessible, with a degree of permissibility, to civil society, employers and other government agencies.

Today's educational models promote the development of an analytical thinking of the graduate's future. This must be balanced by focusing on synthetic and practical aspects. In an era of digitization, it is necessary to promote the use of innovative teaching methods, which are based on the students' active and experiential learning. It is necessary to introduce project-based activities, personalized learning, and enhanced use of ICT in their activities.

\section{Relevance and importance of study}

An important factor in the implementation of digitization is determined by the educational innovation. According to the European Innovation Scoreboard (2017), Romania's performance declined by $14.1 \%$ from $47.9 \%$ in 2010 to $33.8 \%$ in 2016 (Table 1). 
European Innovation Scoreboard on Education Component 2017

\begin{tabular}{|l|c|}
\hline Romania & Change between 2010-2016 \\
\hline Summary of innovation indicator & $-14,1$ \\
\hline Human resources & 7.4 \\
\hline New PhD graduates & $-3,6$ \\
\hline
\end{tabular}

The awareness of the quality management role in a dynamic climate leads to the idea that activity must focus on creativity and innovation, in the context of an increasingly globalized economy. In the last decades there is a growing emphasis on a new managerial optics, with a holistic vision, characterized by autonomy and complementarity, giving up the pyramid vision.

The development of the educational organization, from Păun's perspective (1999), is the product of a multitude of factors, but the management factor has a visible influence, representing an integrative dimension that unites in a structured all the other characteristics of the organization. There are four key components that help public school headmasters lead without having to control in a context of innovation (Senge et al., 2016): systematic thinking, involvement, leadership, learning consciousness. The steps towards an innovative visionary management were materialized as follows: creating a vision for drastic changes in education; focus on reducing quality gaps; hiring key actors in decision-making; investment in professional development of teachers; sharing best practices by connecting to programs; creating professional networks for connecting people and exchanging information.

According to UNESCO (2008), the successful integration of ICT into education largely depends on the teacher's ability to structure the learning environment based on traditional methods and teamwork. However, the use and involvement of ICT in education has not yet been understood as an instrument through which meaningful learning can be generated. Mestres (2008) believes that frequent mistakes at school minimize ICT as a tool that allows access to information transmission, a misconception that continues to affect, including the traditional education. Herrera (2015) states that technology and its contributions evolve and produce very rapid change of knowledge fields. Adeoye et al. (2013) states that the increasing use of ICT as a tool of everyday life increases the quality of life and the learning of students. Through use, changes in the way students are taught are supported, from a teacher-centred curriculum to a student-centred curriculum (Lau\&Sim, 2008), which states that introducing ICT into the educational system promotes profound, innovative learning, depending on the learners' needs.

This whole process of using ICT in education has been supported by constructive, innovative learning environments, with major advances in the development of the Internet and other related technologies (Newhouse, 2002). More and more applications are being created that give students the opportunity to prepare for a future profession, a career in science, or daily life. These include serious games, virtual 3D realities and simulators. Applications on smart phones can also support "real" learning activities at work, for example. The augmented reality, for example through Google Glass, can determine what information is required by the student.

The technological means used to organize the teaching activity are necessary, both for teaching purposes and for assimilation or evaluation. They can also be used for material support. The technical means can be used in the following types of activities (Sava, 2003): interknowledge, practice, application, direct guidance and teamwork, etc. The organization of didactic activity, the methods used by the teacher, are a decisive factor in the students' motivation and performance.

Starting from the OECD test (TALIS, 2013), we can say that school activities defined by attitudes and teaching practices may be relevant to improving the expected effect of school activity through the following effects: teachers who have individual or collaborative research, participate in observation visits to other educational units, practice methods using information and communication technology (ICT); teachers who have a positive atmosphere in class, use 
group work, but also information and communication technology (ICT), motivate students to learn; teachers must practice a variety of evaluation methods, accompanied by immediate feedback; the teaching-learning process is not influenced by the variables in the school environment, at the international level, teachers spend about $80 \%$ of their time in the teachinglearning process, and in Romania this percentage is $82 \%$. Also, the use of teaching methods can be affected by other factors (TALIS, 2013): gender, subjects taught, formal education and training, atmosphere within the school and classroom atmosphere.

A positive classroom atmosphere encourages students to engage in learning, and a positive atmosphere in the school encourages students to socialize. Teaching methods used by teachers can be of significant importance in the way learners teach. According to the same study, there are three types of practices reported by teachers as the most commonly used in Romania (TALIS, 2013): verifying student books or topics, repeating similar work tasks, and presenting a summary of recently learned content.

More often than that, ideas and practices developed in a specific context are driven by policy makers, from top to bottom, by what is called implementation.

Starting from the organizational culture, Wagner (2014) considers that the educational unit is an institutional framework in which the young peoples' capacities to become innovators develop, having as basic abilities: motivation, critical thinking skills, corroborated with teamwork, solving interdisciplinary issues, intrinsic incentives, play and conferring power. In a traditional management, peoples' behaviour is controlled, learning organizations are investing in improving reflection, quality of thinking, and teamwork.

\section{Research methodology}

The investigative approach on the importance of introducing digitization into managerial performance, a process that leads to higher performance in education, consisted of an analysis of the answers of the headmasters from Dambovita County to a questionnaire. Based on the calculation of the sample, the criteria related to the sex and the residence environment were based on a confidence interval of $95 \%$, with a margin of error of $5 \%$ (table 2 ). The information processing methods involved Pearson type correlations and concurrent analysis of multiple data strings (main component analysis and multiple correspondences analysis, respectively).

$\left.\begin{array}{|l|l|}\hline \text { Margin of error } & 5 \% \\ \hline \text { Level of trust } & 95 \% \\ \hline \mathrm{N} \text { (sample measure for 223 } \\ \text { headmasters and deputy masters in } \\ \text { the school year 2017-2019 in } \\ \text { Dambovita county) }\end{array}\right)$

Table 2

The objective of research is about identifying the importance of introducing digitization into managerial performance. Qualitative research on the introduction of digitization in pre-university education is based on the following hypothesis: there is a direct link between digitization and performing managerial activity.

\section{Results}

Following the questionnaire application the following data were extracted:

(A) Using Pearson type correlations, we can identify the following strong correlations. 
In the educational organization, where the headmasters who had the activity of observing how classroom training by digitization (X1) by the teachers were involved and carried out the following activities:

- have also taken measures to support teachers collaboration and have encouraged new teaching methods by digitizing (X2) - 0.663, p $<0.01$; $<0.01$;

- solved problems related to school timetable using educational software $(X 7)-0.632, \mathrm{p}$

- stimulated teamwork in projects targeting digitization (X10) - 0.652, $\mathrm{p}<0.01$;

- implemented an entrepreneurial culture (X13) - 0.693, p $<0.01$.

Taking action on teacher collaboration and encouraging new teaching practices (X2), headmasters favoured the following activities:

- measures on teacher empowerment related to student outcomes through on-line contests (X4) - 0.777, $\mathrm{p}<0.01$;

- providing pupils with digitization results $(\mathrm{X} 5)-0.645, \mathrm{p}<0.01$;

- stimulating creative thinking (X11) - 0.659, $\mathrm{p}<0.01$;

- implementation of an entrepreneurial culture (X13) - 0.618, $\mathrm{p}<0.01$.

By taking measures to improve teachers' teaching practice (X3), headmasters were also involved in such activities:

- verification of administrative procedures and reports in the school (X6) - 0.639, p < 0.01 ;

- stimulation of teamwork in projects aiming at digitization (X10) - 0.715, p $<0.01$.

The headmasters who took action on teacher responsibility in achieving student outcomes (X4) also initiated the following activities:

- providing students with pupils' results through digitization (X5) - 0.614, $\mathrm{p}<0.01$;

- verifying the procedures and administrative reports by digitization (X6), the headmasters also stimulated teamwork through digitization projects $(\mathrm{X} 10)-0.620, \mathrm{p}<$ 0.01 ;

- due to the collaboration with the headmasters of other schools through on-line networks (X9), the headmasters were able to motivate teachers and pupils (X12) - 0.635, $\mathrm{p}<0.01$

- the headmasters who stimulated the development of creative thinking (X11) led to the motivation of teachers and pupils $(\mathrm{X} 12-0,746, \mathrm{p}<0,01)$ and the development of an entrepreneurial culture X13 - 0,686, p $<0,01$.

(B) By Analysing the main components, applying the Varimax rotation (7 interactions) with Kaiser normalization, the following main components were identified (table 3):

Component 1 - if the headmaster increased teachers' responsibility towards pupil's digitization results $(\mathrm{X} 4,-0,484)$ and initiated interdisciplinary school-based projects based on digitization $(\mathrm{X} 8,-0,452)$, then a fall in unpleasant safety was observed: X14 (0.693).

Component 2 - Developing entrepreneurial thinking (X13, 0,904) is favoured by the following: pursuing classroom training through digitization (X1, 0,726); support collaboration between teachers to develop new digitization teaching practices (X2, 0.633); teamwork (X10, 0.563); stimulating creative thinking through digitization (X11, 0.611).

Component 3 - Verifying administrative procedures and reports in school using digitization (X6, 0.909) has improved the following: Measures to improve teachers' teaching abilities (X3, 0.817); Increasing teachers' responsibilities towards students outcomes (X4, 0.403); Stimulation of teamwork (X10, 0.704).

Component 4 - Collaboration with headmasters of other schools through digitization networks (X9, 0.808) has found new ways to motivate teachers and students (X12, 0.805), 
develop creative thinking $(\mathrm{X} 11,0.646)$ and reduce intimidation or abuse $(\mathrm{X} 14,-0.419)$, and to a lesser extent the cases of school theft (X19, -0.346).

Component 5 - Informing parents about pupils' school performance (X5, -0,540) has led to lower student delays in school.

Analysis of the main components using the Varimax rotation method (7 iterations) with Kaiser normalization applied to the arguments X1, X2, X3, X4, X5, X6, X7, X8, X9, X10, $\mathrm{X} 11, \mathrm{X} 12, \mathrm{X} 13, \mathrm{X} 14$. - based on the headmasters' replies

$\mathrm{X} 1$ - Indicate how often you have been involved in the following activities in the last 12 months? [we have noticed how classroom training takes place by digitization;]

X2 - Please indicate how often you have been involved in the following activities in the last 12 months? [we have taken steps to support teacher collaboration with a view to developing new digitization teaching practices;

X3 - Please indicate how often you have been involved in the following activities in the last 12 months? [we have taken steps to ensure that teachers improve their teaching skills;

$\mathrm{X} 4$ - Indicate how often you have been involved in the following activities in the last 12 months? [we have taken steps to ensure teacher accountability for student results through on-line contests;

X5 - Indicate how often you have been involved in the following activities in the last 12 months? [we have provided parents with information on students performance with digitization;]

X6 - Indicate how often you have been involved in the following activities in the last 12 months? [we have checked the administrative procedures and reports in the school through digitization; ]

X7 - Indicate how often you have been involved in the following activities in the last 12 months? [we have solved school timing problems with software;

X8 - Indicate how often you have been involved in the following activities in the last 12 months? [we have initiated interdisciplinary school-level projects targeting digitization;]

X9 - Indicate how often you have been involved in the following activities in the last 12 months? [we have collaborated with headmasters from other schools through online networks; ]

X10 - Indicate how often you have been involved in the following activities in the last 12 months? [we have stimulated teamwork in projects targeting digitization;]

$\mathrm{X} 11$ - Please indicate how often you have been involved in the following activities in the last 12 months? [we have stimulated creative thinking skills through digitization;]

$\mathrm{X} 12$ - Indicate how often you have been involved in the following activities in the last 12 months? [we have initiated actions to motivate teachers and students by offering digitized resources;

X13 - Mention how often you have been involved in the following activities in the last 12 months? [we have implemented an entrepreneurial culture.]

X20 - To what extent do you encounter the following safety and school discipline situations in your institution? [intimidation or verbal abuse among students (including through sms, e-mail)]

\begin{tabular}{|l|l|l|r|r|r|l|}
\hline & \multicolumn{7}{|c|}{ Component } \\
\cline { 2 - 7 } & \multicolumn{1}{|c|}{1} & \multicolumn{1}{|c|}{2} & 3 & 4 & 5 & \multicolumn{1}{c|}{} \\
\hline $\mathrm{X} 1$ & $-0,026$ & $\mathbf{0 , 7 2 6}$ & 0,212 & 0,107 & $\mathbf{0 , 4 5 6}$ & $-0,126$ \\
\hline $\mathrm{X} 2$ & $-0,170$ & $\mathbf{0 , 6 3 3}$ & 0,283 & 0,320 & $\mathbf{0 , 4 9 7}$ & 0,118 \\
\hline $\mathrm{X} 3$ & 0,021 & 0,326 & $\mathbf{0 , 8 1 7}$ & 0,179 & 0,021 & 0,227 \\
\hline $\mathrm{X} 4$ & $\mathbf{- 0 , 4 8 4}$ & 0,291 & $\mathbf{0 , 4 0 3}$ & 0,232 & $\mathbf{0 , 4 8 6}$ & $-0,162$ \\
\hline $\mathrm{X} 5$ & 0,031 & 0,337 & 0,288 & 0,357 & $\mathbf{0 , 5 0 2}$ & $\mathbf{- 0 , 5 4 0}$ \\
\hline $\mathrm{X} 6$ & $-0,019$ & $-0,074$ & $\mathbf{0 , 9 0 9}$ & $-0,077$ & 0,191 & $-0,031$ \\
\hline $\mathrm{X} 7$ & 0,171 & 0,194 & 0,112 & 0,156 & $\mathbf{0 , 8 5 6}$ & 0,052 \\
\hline $\mathrm{X} 8$ & $\mathbf{- 0 , 4 5 2}$ & $-0,023$ & 0,125 & 0,245 & 0,369 & 0,281 \\
\hline
\end{tabular}




\begin{tabular}{|l|l|l|l|l|r|c|}
\hline & \multicolumn{7}{|c|}{ Component } \\
\cline { 2 - 7 } & \multicolumn{1}{|c|}{1} & \multicolumn{1}{|c|}{3} & \multicolumn{1}{c|}{5} & 5 & 6 \\
\hline $\mathrm{X} 9$ & $-0,012$ & 0,003 & 0,016 & $\mathbf{0 , 8 0 8}$ & 0,275 & $-0,057$ \\
\hline $\mathrm{X} 10$ & $-0,086$ & $\mathbf{0 , 5 6 3}$ & $\mathbf{0 , 7 0 4}$ & $-0,006$ & 0,111 & 0,131 \\
\hline $\mathrm{X} 11$ & $-0,295$ & $\mathbf{0 , 6 1 1}$ & $-0,112$ & $\mathbf{0 , 6 4 6}$ & 0,025 & 0,130 \\
\hline $\mathrm{X} 12$ & $-0,246$ & 0,354 & 0,070 & $\mathbf{0 , 8 0 5}$ & 0,057 & 0,073 \\
\hline $\mathrm{X} 13$ & $-0,067$ & $\mathbf{0 , 9 0 4}$ & 0,106 & 0,099 & 0,042 & 0,007 \\
\hline $\mathrm{X} 14$ & $\mathbf{0 , 6 9 3}$ & 0,313 & $-0,307$ & $\mathbf{- 0 , 4 1 9}$ & $-0,132$ & 0,092 \\
\hline
\end{tabular}

(C) Multiple-Correspondences Analysis (MCA) - It is noted that headmasters have been involved in the same way over the past 12 months to increase teachers' responsibility for pupil outcomes by introducing digitization. This is also evident from the very low standard deviation (0.46089). In solving problems with timetables with software, headmasters were most involved in the past 12 months. There are major differences in the involvement of teachers in entrepreneurial activity (this is shown by the very large deviation of 1.32842 standard deviation). Some headmasters have very busy entrepreneurial activity, others do not have it at all. Too low average in X14 (2.0000) demonstrates that almost all headmasters are confronted with classroom disturbances, that is, this problem is a common problem (table 4).

\section{Multiple-Correspondence Analysis}

Table 4

\section{Minimum, maximum, average, and standard deviations for X1 - X14, based on} headmasters' responses

\begin{tabular}{|l|c|c|c|c|c|}
\hline & $\mathbf{N}$ & Minimum & Maximum & Average & $\begin{array}{c}\text { Standard } \\
\text { Deviation }\end{array}$ \\
\hline X1 & 142 & 4,00 & 5,00 & 4,4444 & 0,51131 \\
\hline X2 & 142 & 4,00 & 5,00 & 4,3889 & 0,50163 \\
\hline X3 & 142 & 2,00 & 5,00 & 4,0000 & 0,84017 \\
\hline X4 & 142 & 4,00 & 5,00 & 4,2778 & $\mathbf{0 , 4 6 0 8 9}$ \\
\hline X5 & 142 & 4,00 & 5,00 & 4,3333 & 0,48507 \\
\hline X6 & 142 & 2,00 & 5,00 & 4,3333 & 0,76696 \\
\hline X7 & 142 & 4,00 & 5,00 & 4,6667 & 0,48507 \\
\hline X8 & 142 & 2,00 & 5,00 & 3,8889 & 0,96338 \\
\hline X9 & 142 & 1,00 & 5,00 & 4,3333 & 0,97014 \\
\hline X10 & 142 & 2,00 & 5,00 & 4,4444 & 0,78382 \\
\hline X11 & 142 & 2,00 & 5,00 & 3,8333 & 1,09813 \\
\hline X12 & 142 & 2,00 & 5,00 & 3,7222 & 1,01782 \\
\hline X13 & 142 & 1,00 & 5,00 & 3,0000 & $\mathbf{1 , 3 2 8 4 2}$ \\
\hline X20 & 142 & 1,00 & 3,00 & $\mathbf{2 , 0 0 0 0}$ & 0,68599 \\
\hline Valid variables & 142 & & & & \\
\hline
\end{tabular}

\section{Conclusion}

Starting from the premise that the digital revolution transforms activity and reorganization of activity is necessary, education has an important role to play in increasing the number of competitive people on the European market. The school manager must keep pace with technical and technological progress and adopt innovative processes to keep the educational unit performing in a dynamic environment. 
The Matrix on Introducing Digitization in Educational Unit Management

\begin{tabular}{|l|l|}
\hline Digitized process & Performance \\
\hline $\begin{array}{l}\text { Introduction of new teaching methods through } \\
\text { digitization }\end{array}$ & $\begin{array}{l}\text { High collaboration among teachers; } \\
\text { High attractiveness among students. }\end{array}$ \\
\hline $\begin{array}{l}\text { Introducing educational software and digitization } \\
\text { into operational processes, both at the didactic level } \\
\text { and at administrative level }\end{array}$ & $\begin{array}{l}\text { Effective timetable; } \\
\text { Increasing project implementation through team } \\
\text { collaboration; } \\
\text { Implementing an entrepreneurial culture; } \\
\text { Improving class results; } \\
\text { Increasing student results through on-line contests; } \\
\text { High and effective communication with parents; } \\
\text { Effective reporting in the management process. }\end{array}$ \\
\hline Collaboration through on-line networks & $\begin{array}{l}\text { Increasing the motivation and performance of the } \\
\text { human resource. }\end{array}$ \\
\hline
\end{tabular}

Acknowledgement: This work is supported by project POCU 125040, entitled "Development of the tertiary university education to support the economic growth - PROGRESSIO", cofinanced by the European Social Fund under the Human Capital Operational Program 2014-2020

\section{References}

1. Adeoye, Y.M., Oluwole, A.F. and Blessing, L.A. (2013), Appraising the Role of Information Communication Technology (ICT) as a Change Agent for higher education in Nigeria, International Journal of Educational Administration and Policy Studies. Vol 5 (8), pp. 177-183.

2. Aguilar, M. (2012), Aprendiraje y Tecnologias de Información y Comunicación: Hacia nuevos escenarios educativos, Revista Latinoamericana de Ciencias Sociales, Niñery Juventud, 10 (2), pp. 801-811.

3. EnGauge (2002), 21st Century Skills, NCREL, Metiri Group, bttp:// www.cwasd.k12.wi.us/ highschl/ newsfile1062_1.pdf.

4. Herrera, A. (2015), Una mirada reflexiva sobre las TIC en Educación Superior, Revista Electrónica de Investigación Educativa. 17 (1), pp. 1-4.

5. Lau, B.T and Sim, C.H. (2008), Exploring the Extent of ICT adoption among Secondary School Teachers in Malaysia, International Journal of Computing and ICT research Vol., 2, No. 2.

6. Mestres, L. (2008), La alfabetización digital de los docentes, bttp:// wnw.educaweb.com/noticia/2008/12/01/ alfabetizacion-digital-docentes-3349/

7. Newhouse, C.P. (2002), Literature review. The impact of ICT on Learning and Teaching, Perth, Australia, Western Australian Department of Education, wnw.det.wa.edu.au/education/cmis/eval/downloads/pd/impactreview.pdf.

8. Păun, E. (1999), Școala - abordare sociopedagogică, Polirom, Iași.

9. Sava, S. (2003), Teorie și practică în educația la distanță, Didactică şi Pedagogicăa, Bucharest.

10. Senge, P., Cambron-McCabe, N., Lucas, T., Smith, B., Dutton, J. and Kleiner, A. (2016), Scoli care invață: a cincea disciplină aplicată în educație, Trei, Bucharest.

11. TALIS (2013), Results: An International Perspective on Teaching and Learning (OECD, 2014), p. 172.

12. UNESCO (2008), ICT competency standards for teachers, bttp:// unesdoc.unesco.org/images/0015/001562/156207e.pdf.

13. Wagner, T. (2014), Formarea inovatorilor. Cum crești tinerii care vor schimba lumea de mâine, Trei, Bucharest.

14. ***(2014), Education for the 21st Century. A synthesis of ideas, Harvard University Advanced Leadership Initiative Think Tank, https://globaled.gse.harvard.edu/files/geii/files/2014_education_report_web.pdf. 